\title{
Simulation of printed circuit boards recycling process
}

\author{
Dagmar Janacova ${ }^{1,}$, Jan Pitel $^{2}$, Vladimir Vasek $^{1}$, Pavel Mokrejs ${ }^{1}$, Miluse Viteckova ${ }^{3}$, Rudolf Drga $^{1}$ and Jiri Krenek ${ }^{1}$ \\ ${ }^{1}$ Tomas Bata University in Zlín, Faculty of Applied Informatics, nam. T.G.Masaryka 5555, 76001 Zlín, Czech Republic \\ ${ }^{2}$ Technical University of Košice, FMT, Bayerova 1, 08001 Prešov, Slovakia \\ ${ }^{3}$ VSB - Technical University of Ostrava, Faculty of Mechanical Engineering, 17.listopadu 15,708 33 Ostrava, Czech Republic
}

\begin{abstract}
This paper focused on the modeling of ecological PCB. Due to the high increase in the production of electronic waste, which contains a whole range of usable components, it is necessary to recycle it. About the study of the issue, we have proposed a solution for the separation of conductive paths from plastic and taking into account the legislative approaches and taking into account the existing methods of PCB separation, the composition, and production of PCBs and also the binders used in PCBs. We used the knowledge of process engineering to design a mathematical description of temperature fields in $\mathrm{PCB}$ and stress. To a great extent, we have devoted ourselves to the simulation experiments of PCB heating and cooling and the determination of temperature fields and stress due to temperature, cyclic mechanical stresses due to temperature. The simulation is performed in the Pro/ENGINEER and COMSOL Multiphysics ${ }^{\circledR}$ software environments, because of the possibility of solving multi-physical problems. Outputs from computer simulations are the initial stage for designing an eco-friendly way of recycling PCBs. In the future, we will focus on the more difficult issue of recycling multilayer PCBs. The development of new criteria for PCB recycling has opened new possibilities of treatment for used materials.
\end{abstract}

\section{Introduction}

The situation with an increase in electronic waste has never been as up-to-date as it is today, for reasons of a major upgrading of such equipment. Electronic appliances surround us, and this electronics has a very short lifetime, due to the modernization of these devices. On the other hand, it means that the older electronics are getting deeper and deeper into the waste. The scraper is very diverse, and therefore, recycling requires a high degree of separation. In our work, we focused on the special part that is present in every electronic device on the DSP. We have focused on the ecological separation of copper conduction paths from printed circuit boards due to thermal stress because they are based on a physical principle.

\section{PCB materials}

For surface assembly, the PCB material should have approximately the same coefficient of linear expansion as the material of the used parts. For reason of different heat dilatation PCB and parts, was growing the mechanical stress of soldered joint. However, at the same time, the magnitude of mechanical stress is given by the difference between the linear expansion coefficients [1]. According to previous experiences, in common application of surface mount assembly on a glass-epoxide PCB (FR4) it is possible (with no risk of subsequent cracking of soldered joints) to mount miniature passive parts (resistors, ceramic capacitors) of the size up to $10 \mathrm{~mm}$, integrated circuits in SO version, plastic microchip carriers, flat pack and quad pack circuits, TAB (Micropack) etc. At present, the European producers provide boards of thicknesses varying from 0.8 to $3.2 \mathrm{~mm}$; the preferred thickness is $1.6 \mathrm{~mm}$. Copper foils are produced in thicknesses 35 $\mu \mathrm{m}, 70 \mu \mathrm{m}$ and $105 \mu \mathrm{m}$, possibly thicker. The FR4 materials are provided with copper foils of $18 \mu \mathrm{m}$, $9 \mu \mathrm{m}$ or $5 \mu \mathrm{m}$ in thickness. The thinnest foils are used for the softest joints, which is the case of some special surface mount assembly applications [5].

\subsection{The thermal separation of PCBs}

When the solid body temperature changes, the body dimensions change. This is thermal expansion. For bodies that have a predominant length, we talk about thermal length expansion. Thermal expansion is a consequence of the distancing of mean distances between the particle of a substance due to its greater misalignment. The dependence of the elongation on the type of material is expressed using the temperature coefficient of the length expansion $\alpha[3,6]$.

\footnotetext{
*orresponding author: janacova@utb.cz
} 
The calculation of shear stress needed for division of two proceeded boards from Hook's law.

$$
\sigma=E \cdot \varepsilon
$$

where $\quad \sigma$ is the resulting shear stress $[\mathrm{Pa}]$

$E$ is the modulus of elasticity [Pa]

$\varepsilon$ is a relative elongation [1]

In the resulting quadratic equation, it is necessary to include also the linear thermal expansion of solid bodies.

$$
l=l_{0} \cdot(\alpha \cdot \Delta T+1)
$$

Where $\quad \alpha$ is linear coefficient expansion $\left[\mathrm{K}^{-1}\right]$

$\Delta T$ is temperature difference $[\mathrm{K}]$

$l_{0}$ is the original length of the material [m]

Rearrangement and the subsequent fusion both quadratic equations give the following relation for calculation of shear stress of one board.

$$
\sigma=E \cdot \alpha \cdot \Delta T
$$

Resulting force enumeration:

$$
F_{T}=\left(\sigma_{1}-\sigma_{2}\right) \cdot S_{j}
$$

where $\quad F_{T}$ is resulting in power [N]

$\sigma_{l}$ is the pulling stress in the first material $[\mathrm{Pa}]$ $\sigma_{2}$ is the pulling stress in the sec. material [Pa] $S_{j}$ is the contacts surface of both material $\left[\mathrm{m}^{2}\right]$

To calculate the amount of shear stress needed to split the two boards, we used the Hook's law.
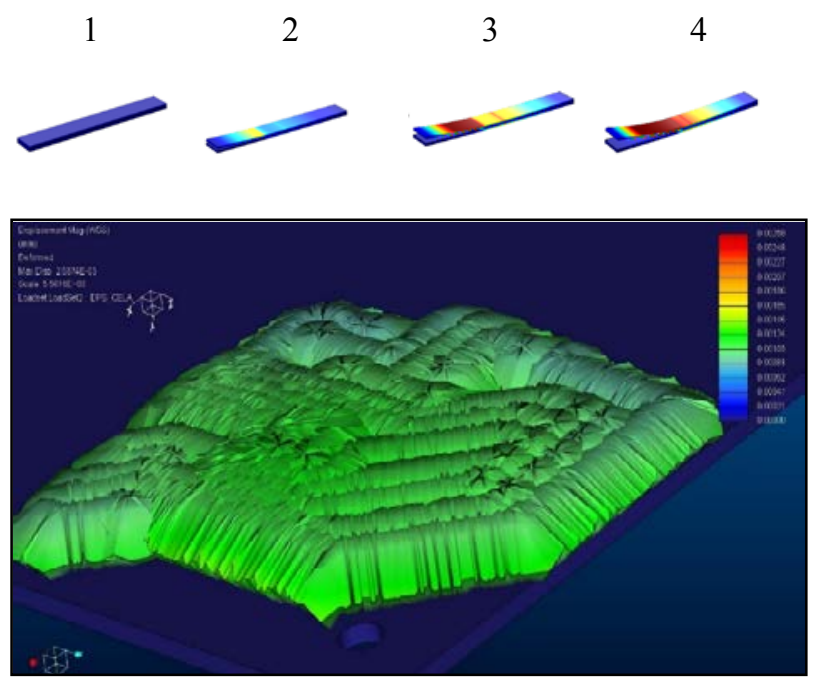

Fig. 1. Linear expansion of materials during heating 1,2,3,4, longitudinal display in Pro / ENGINEER software

This power must be higher than the allowed shear stress in the given materials. We obtain the following equation:

$$
\frac{F_{T}}{S_{j}}>\tau_{s}
$$

where $T_{s}$ is the maximum permitted shear stress of the material [MPa].

For this calculation, we selected the combination of epoxide resin and copper. In the literature [2, 9], we found the basic characteristics of the used materials needed for calculation - Table 1. The calculation shows the value of depending force depending on temperature variation, which is necessary to divide the copper layer from the surface of epoxide resin.

Table 1. Mechanical properties of the material

\begin{tabular}{|c|c|c|}
\hline & epoxide resin & copper \\
\hline $\boldsymbol{E}(\mathbf{P a})$ & $1,4 \cdot 10^{6}$ & $13 \cdot 10^{10}$ \\
\hline$\alpha\left(\mathbf{K}^{-1}\right)$ & $13 \cdot 10^{-6}$ & $17 \cdot 10^{-6}$ \\
\hline
\end{tabular}

The resulting shear stress is given in N.mm-2. For brazing solders it is $t_{s}=200 \mathrm{~N} . \mathrm{mm}^{-2}$ [5]. The calculation for other $T$ showed that the shear stress critical limit, 200 N.mm ${ }^{-2}$ for $S_{j}=10 \mathrm{~mm}^{2}$ is exceeded at $\Delta T=91 \mathrm{~K}$ on Table $2[2,11]$.

Table 2. Calculation of shear stress $\tau$

\begin{tabular}{|c|c|c|c|c|c|}
\hline $\begin{array}{c}\Delta \mathbf{T} \\
{\left[\mathbf{K}^{-1}\right]}\end{array}$ & $\begin{array}{c}\mathbf{C u} \\
\sigma[\mathrm{Pa}]\end{array}$ & $\begin{array}{c}\text { epoxide } \\
\text { resin } \\
\boldsymbol{\sigma}[\mathrm{Pa}]\end{array}$ & $\begin{array}{c}\text { Surface } \\
{[\mathbf{m m} 2]}\end{array}$ & $\begin{array}{c}\text { Force } \\
{[\mathbf{N}]}\end{array}$ & $\begin{array}{c}\tau \text { of materials } \\
{[\mathbf{N} / \mathbf{m m} 2]}\end{array}$ \\
\hline 85 & 187850000 & 1547 & 10 & 1878,485 & 187,84 \\
\hline 86 & 190060000 & 1565,2 & & 1900,584 & 190,05 \\
\hline 87 & 192270000 & 1583,4 & & 1922,684 & 192,26 \\
\hline 88 & 194480000 & 1601,6 & & 1944,784 & 194,47 \\
\hline 89 & 196690000 & 1619,8 & & 1966,884 & 196,68 \\
\hline 90 & 198900000 & 1638 & & 1988,984 & 198,89 \\
\hline 91 & 201110000 & 1656,2 & & 2011,083 & 201,10 \\
\hline 92 & 203320000 & 1674,4 & & 2033,183 & 203,31 \\
\hline 93 & 205530000 & 1692,6 & & 2055,283 & 205,52 \\
\hline 94 & 207740000 & 1710,8 & & 2077,383 & 207,73 \\
\hline 95 & 209950000 & 1729 & & 2099,483 & 209,94 \\
\hline 96 & 212160000 & 1747,2 & & 2121,583 & 212,6 \\
\hline 97 & 214370000 & 1765,4 & & 2143,682 & 214,37 \\
\hline 98 & 216580000 & 1783,6 & & 2165,782 & 216,58 \\
\hline 99 & 218790000 & 1801,8 & & 2187,882 & 218,79 \\
\hline 100 & 221000000 & 1820 & & 2209,982 & 220,99 \\
\hline 101 & 223210000 & 1838,2 & & 2232,082 & 223,21 \\
\hline 102 & 225420000 & 1856,4 & & 2254,181 & 225,42 \\
\hline 103 & 227630000 & 1874,6 & & 2276,281 & 227,63 \\
\hline 104 & 229840000 & 1892,8 & & 2298,381 & 229,84 \\
\hline 105 & 232050000 & 1911 & & 2320,481 & 232,05 \\
\hline
\end{tabular}

\subsection{Shear stress simulation process in $\mathrm{PCB}$}

In Pro/ENGINEER, We chose Pro/Mechanics. We picked material from the materials library and assigned geometry. The advantage of this process is that these materials already contain all the properties and physical quantities suitable for simulation - Figure 2. In the next step, We defined the heating at $260^{\circ} \mathrm{C}$ and boundary conditions. In this simulation, and warming up the PCB. 
Once the temperature analysis completed and We used the resulting temperature distribution for structural analysis [7].
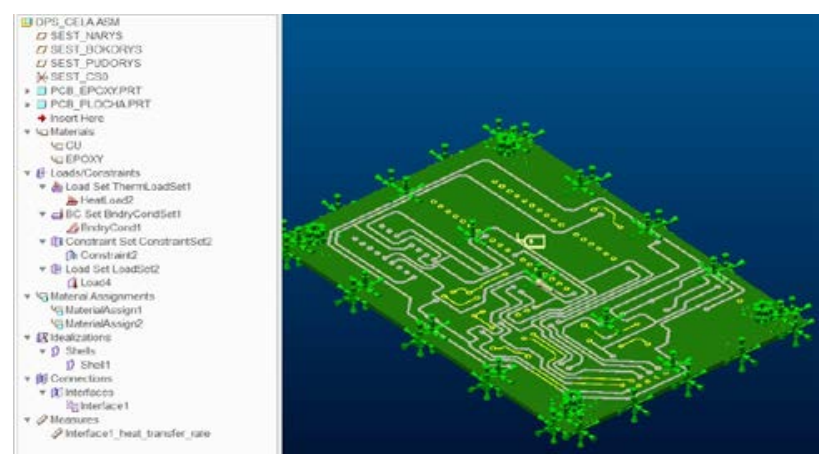

Fig. 2. The model DPS with defined conditions for the simulation

Due to the different lengths of the material, the tension between the materials and the accompanying phenomenon - the shear stress - became apparent. The result of this analysis presented in Figure 3. The maximum strain occurred at a point shown a red arrow. The value of this stress is $492 \mathrm{MPa}$ [10].

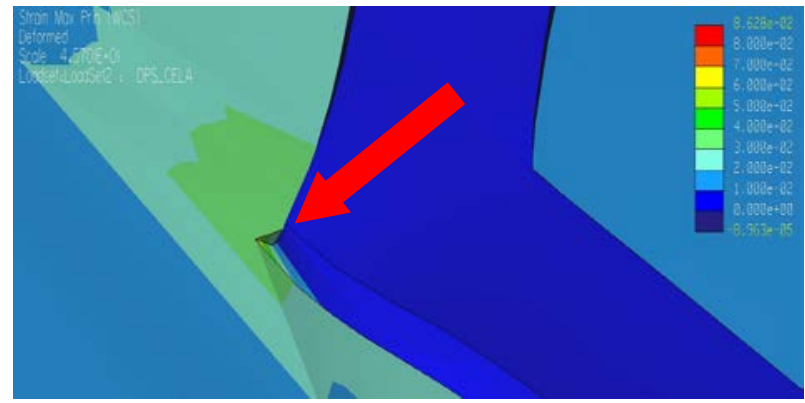

Fig. 3. The maximum stress value of $492 \mathrm{MPa}$.

The temperature distribution is shown in Figure 4. The maximum heating temperature reached $225^{\circ} \mathrm{C}$. It is also apparent from the figure that the resulting temperature at the heating point depends on the length of the copper conducting paths. During this simulation, the heat flow was gradually removed by the longer copper paths from the heated area and thereby cooled. The paths, which were short or directly ended in the heated area, warmed to a higher temperature $[9,10]$. The direct influence of unheated copper paths heated by conductive copper paths. Where paths are too close, we can expect less stress than a place where the paths are far apart.

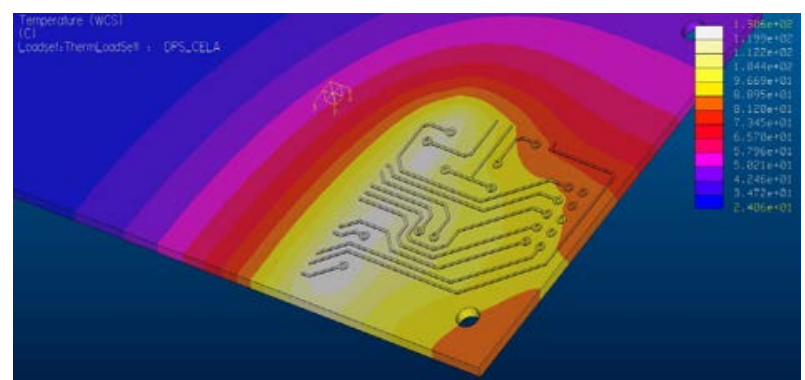

Fig. 4. The final temperature distribution in PCB. Heating with power $100 \mathrm{~mW}$

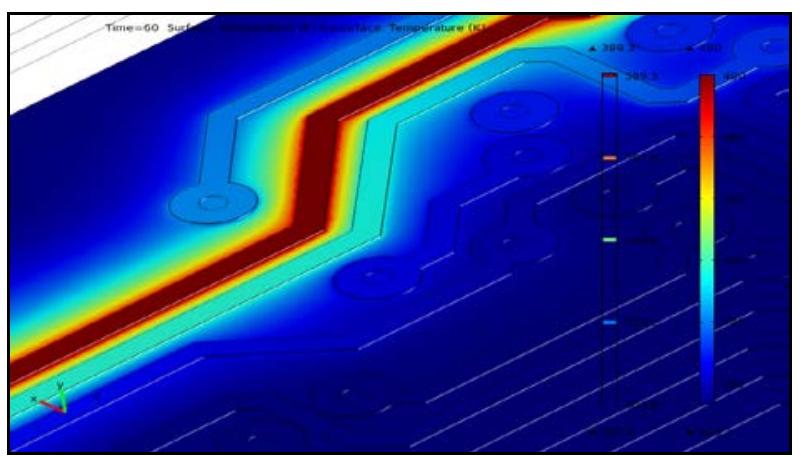

Fig. 5. View of the DPS with warmed paths at $400 \mathrm{~K}$ for time $60 \mathrm{~s}$.

One result is the stress distribution, and further information is the PCD deformation due to stress, as can be seen from Figure 6 .

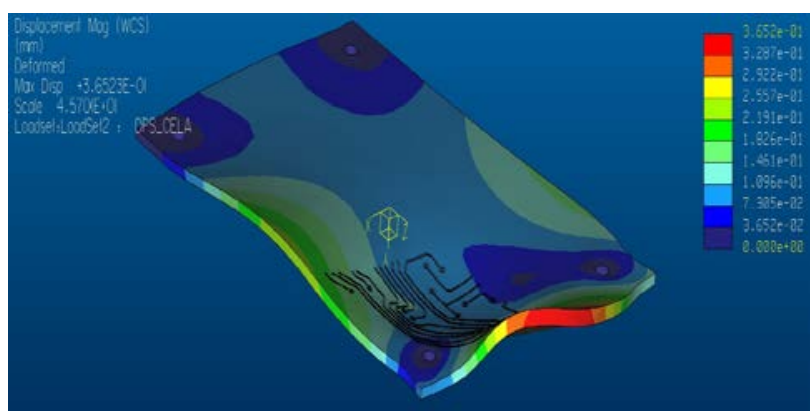

Fig. 6. PCB deformation due to stress.

\section{Results of the separation performed under laboratory conditions}

Separating copper paths from PCBs at separation in the laboratory is shown in Figure 7 for an older type of PCB. The principle was to carry out cyclical thermal stresses, heating, and hard-drying PCBs [7, 10].

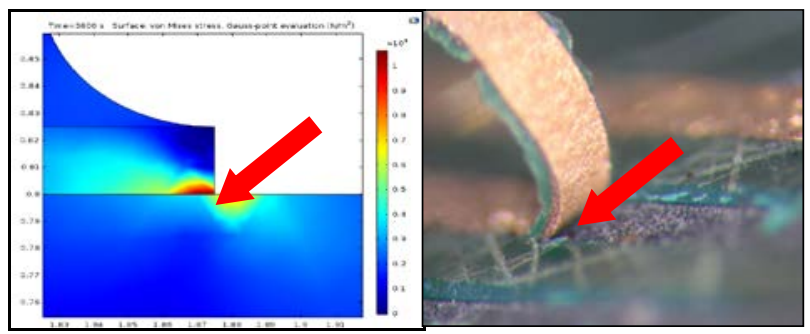

Fig. 7. Views of separating copper paths from the PCB from simulation and in the separation in the laboratory under the microscope.

The required shear stress proceeds from the edge of the copper conductive path to its center. Images were taken using a stereomicroscope at a magnification of 5.6 times, and present the results of the tests performed in the laboratory. We see peeling conductive copper paths from 
Pictures of separating copper paths from the PCB from simulation and in the separation in the laboratory [7].

In our experiments, we have used several methods of heating of the PCB. Heating PCB at a press tempered at $200{ }^{\circ} \mathrm{C}$, further microwave heating. Was the most effective heating with a heat gun to $350^{\circ} \mathrm{C}$. This temperature is sufficient even for the separation of tin because the melting point of tin is $250{ }^{\circ} \mathrm{C}$. After using mechanical separation, parts dropped away from the PCB. We used a mechanical separation for removal of conductive paths $[7,9]$.

\section{Design of PCB disintegration}

A prerequisite for successful separation of conductive paths from $\mathrm{PCBs}$ is to remove soldered parts. In cooperation with the Institute of Manufacturing Engineering. We created a 3D model of a suitably designed knife that can be used to separate the electronic components from the PCB - Figure 8. Not only parts but can also be cut with the PCB itself on thin sheets. The device may also be used to separate multilayer PCBs [4, 8]. The blade design and part of the device are shown in the figure below.

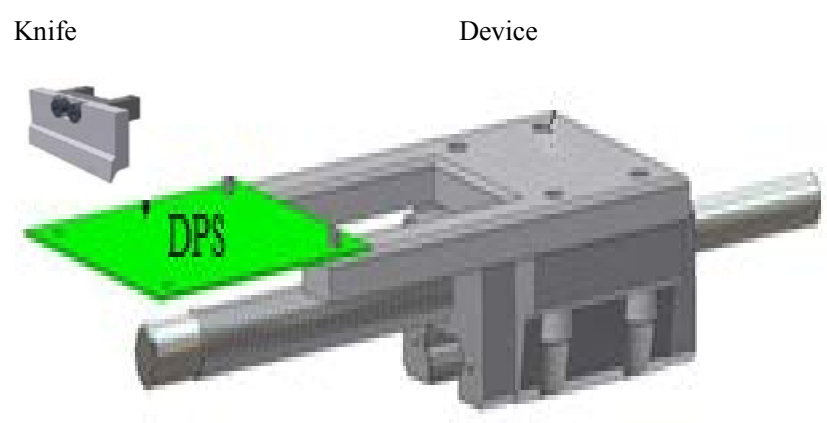

Fig. 8. Disintegration of PCB

\section{Conclusion}

We focused on the urgency and the ways of dealing with electrical waste, both in the Czech Republic and on a global scale. A literature study shows that the increase in electrical waste is alarming, which implies the necessity to process this electrical waste $100 \%$ as possible and without further production of unwanted byproducts. It has been shown that one of such options could be the ecological separation of conductive paths by cyclic thermal loading, based on different temperature longitudinal stretches of materials.

The proposed PCB environmental separation process is based on the calculations and simulations and concerning the environment. We performed the simulation of temperature fields and stresses in the PCB and the calculation of the required shear stress, which is due to the difference in tensile stresses of the two glued materials. Based on the calculations made and concerning subsequent simulations, we have the result of a minimum temperature difference $\Delta T=91 \mathrm{~K}$. With $3 \mathrm{D}$ models and with mathematical modeling results, we performed computer simulations. The results of the simulation are very interesting from the resulting shear stress between the copper path and the epoxy board. Overlapping shear stress was local and, according to defined conditions, appeared intensivelyo $n$ the edge of the copper path. Performed computer simulations we verified in laboratory conditions.

Acknowledgment: This work was supported by the Slovak Research and Development Agency under contract No. APVV-15-0602 and by the Ministry of Education, Youth and Sports of the Czech Republic within the National Sustainability Programme project No. LO1303 (MSMT-7778/2014) and also by the European Regional Development Fund under the project CEBIA-Tech No. CZ.1.05/2.1.00/03.0089

\section{References}

1. F. Božek, R. Urban, Z. Zemánek, Recycling, 202 pp., ISBN 80-238-9919-8, (2002)

2. J. Křenek. Doctoral thesis, 105, FAI UTB, Zlín (2017)

3. Volek, Z. Pospíchal, TT, 48, 25. (2000)

4. D. Janáčová, K. Kolomazník, V. Vašek, P. Mokrejš, 13th WSEAS, ACMOS'11, ISBN 9781618040046, (2011)

5. P. Božek, ICSS 2013, Wroclaw; Poland, (2013)

6. L. Vašek, V. Dolinay, International Journal of Mathematical Models and Methods in Applied Sciences, 4, 4, (2010)

7. J. Křenek, D. Janáčová, O. Líška, V. Vašek, O. Šuba, CSCC 2017, The Journal MATEC Web of Conferences, Crete Island, (2017)

8. D. Seidl, P. Koštial, Z. Jančíková, I. Ružiak, S. Rusnáková, M. Farkašová, CCIS, 188, 1, (2011)

9. Z. Jančíková, P. Koštial, D. Bakošová, I. Ružiak, K. Frydrýšek, J. Valíček, M. Farkašová, R. Puchký, Journal of Nano Research, 16, 21, (2013)

10. D. Janačová, V. Vašek, J. Pitel', M. Vítečková, R. Drga, J. Křenek, O. Líška MATEC Web Conf., 210 01004, eISSN: 2261-236X, DOI:https://doi.org/10.1051/matecconf/2018210010 04, (2018)

11. D. Janáčová, et al. Proceedings of the 6th WSEAS International Conference on Engineering Education - Recent Advantages in Engineering Education. Dondon P (Ed.), Rhodes, Greece, (2009) 